\title{
Sub-3 nm particle size and composition dependent response of a nano-CPC battery
}

\author{
J. Kangasluoma ${ }^{1}$, C. Kuang ${ }^{2}$, D. Wimmer ${ }^{1}$, M. P. Rissanen ${ }^{1}$, K. Lehtipalo ${ }^{1,3}$, M. Ehn ${ }^{1}$, D. R. Worsnop ${ }^{1,4}$, J. Wang ${ }^{2}$, \\ M. Kulmala ${ }^{1}$, and T. Petäjä ${ }^{1}$ \\ ${ }^{1}$ Department of Physics, P.O. Box 64, 00014, University of Helsinki, Helsinki, Finland \\ ${ }^{2}$ Atmospheric Sciences Division, Brookhaven National Laboratory, Upton, New York, 11789, USA \\ ${ }^{3}$ Airmodus Ltd., Finland, Gustaf Hällströmin katu 2 A, 00560 Helsinki, Finland \\ ${ }^{4}$ Aerodyne Research Inc., Billerica, MA, USA \\ Correspondence to: C. Kuang (ckuang@bnl.gov)
}

Received: 1 August 2013 - Published in Atmos. Meas. Tech. Discuss.: 8 October 2013

Revised: 17 January 2014 - Accepted: 30 January 2014 - Published: 4 March 2014

\begin{abstract}
In this study we built a nano-CPC (condensation particle counter) battery, consisting of four ultrafine CPCs optimized for the detection of sub- $3 \mathrm{~nm}$ particles. Two of the CPCs use diethylene glycol as a working fluid: a laminar type diethlylene glycol CPC and a mixing type Airmodus A09 particle size magnifier. The other two CPCs are a laminar type TSI 3025A and a TSI 3786 with butanol and water as the working fluids, respectively. The nanoCPC battery was calibrated with seven different test aerosols: tetraheptyl ammonium bromide, ammonium sulfate, sodium chloride, tungsten oxide, sucrose, candle flame products and limonene ozonolysis products. The results show that ammonium sulfate and sodium chloride have a higher activation efficiency with the water-based 3786 than with the butanolbased $3025 \mathrm{~A}$, whereas the other aerosols were activated better with butanol than with water as the working fluid. It is worthwhile to mention that sub- $2 \mathrm{~nm}$ limonene ozonolysis products were detected very poorly with all of the CPCs, butanol being the best fluid to activate the oxidation products. To explore how the detection efficiency is affected if the aerosol is an internal mixture of two different chemical substances, we made the first attempt to control the mixing state of sub- $3 \mathrm{~nm}$ laboratory generated aerosol. We show that we generated an internally mixed aerosol of ammonium sulfate nucleated onto tungsten oxide seed particles, and observed that the activation efficiency of the internally mixed clusters was a function of the internal mixture composition.
\end{abstract}

\section{Introduction}

Atmospheric aerosols play a significant role in impacting the global atmospheric energy balance by directly scattering the sunlight and indirectly participating in cloud formation and affecting the properties of clouds (IPCC, 2007). According to Merikanto et al. (2010), about $75 \%$ of surface level aerosol particles are formed in the atmosphere via nucleation and condensation of pre-existing vapours, but the processes and vapours responsible for new particle formation are not well known. Recent field (Riipinen et al., 2007; Kuang et al., 2008) and laboratory (Sipila et al., 2010; Kirkby et al., 2011) studies show that while sulfuric acid plays a major role in atmospheric nucleation, compounds that stabilize sulfuric acid in the initial cluster formation and compounds, other than sulfuric acid, that contribute to particle growth above $1.5 \mathrm{~nm}$ are still mostly unknown (Smith et al., 2010; Riipinen et al., 2012; Kuang et al., 2012a).

The chemical composition of particles from 4 to $10 \mathrm{~nm}$ can be measured indirectly with a tandem differential mobility analyser (HTDMA) (Sakurai et al., 2005; Ehn et al., 2007; Keskinen et al., 2013), which measures the hygroscopic and volatile fraction of the sampled aerosols. However, due to large sampling losses associated with low charging, transport and counting efficiencies of the smallest particles, the lowest measurable size for the HTDMA is about $4 \mathrm{~nm}$, with most field measurements restricted to sizes above $10 \mathrm{~nm}$. Alternatively, the chemical composition of the nucleation mode particles can be measured by means of mass spectrometry. 
The thermal desorption chemical ionization mass spectrometer (TD-CIMS) (Voisin et al., 2003) is able to measure the chemical composition of freshly nucleated particles as small as $8 \mathrm{~nm}$. For example, Smith et al. (2010) found that nanoparticle composition was dominated by the presence of aminium salts. A different sampling approach is employed in the nanoaerosol mass spectrometer (NAMS) (Bzdek et al., 2011), where the sample particle is broken into elements, and thereon the elemental distribution is measured. Using this method Bzdek et al. were able to observe the elemental composition of $20 \mathrm{~nm}$ particles. With an atmospheric pressure inlet time of flight mass spectrometer (APi-TOF) (Junninen et al., 2010) it is possible to characterize the precise chemical composition of atmospheric ions up to about $1.5 \mathrm{~nm}$ in mobility diameter, which corresponds to about $1000 \mathrm{Th}$, and by using different ionization methods also information from neutral clusters can be obtained (Zhao et al., 2010; Jokinen et al., 2012; Berndt et al., 2012). These two methods leave a gap between 1.5 and $8 \mathrm{~nm}$, where the measurement of chemical composition (both direct and indirect) has been difficult so far. Also, while measurement of the total aerosol size distribution down to around $2.5 \mathrm{~nm}$ is a routine measurement by DMPS (differential mobility particle sizer) and NAIS (neutral air ion spectrometer) (based on the detection limit for the DMPS using a 3025A as a detector and on the upper size limit of corona-generated ions as seen in Manninen et al. (2011), Aalto et al.(2001) and Manninen et al.(2009)), below that size there is only a very limited literature available (Lehtipalo et al., 2009, 2010; Jiang et al., 2011b; Kuang et al., 2012a; Kulmala et al., 2013) due to lack of instruments capable of measuring sub- $2 \mathrm{~nm}$ neutral clusters.

In earlier studies Kulmala et al. (2007) have inferred aerosol hygroscopicity with a CPC (condensation particle counter)-battery $(\mathrm{CPCb})$ using four $\mathrm{CPCs}$ : an ultrafine water and butanol CPC $(\mathrm{d} 50=3 \mathrm{~nm}$ for silver, where d50 is the size corresponding to $50 \%$ detection efficiency) and a conventional water and butanol CPC $(\mathrm{d} 50=11 \mathrm{~nm})$. In the laboratory, the CPCs were tuned to have equal cut-off diameters for both working fluids for non-hygroscopic silver test aerosol. Using the $\mathrm{CPCb}$ with those operating conditions, they found that salts (hygroscopic test aerosol) are activated better with water than butanol. In the following work Riipinen et al. (2009) were able to infer the hygroscopicities of atmospheric aerosols in Hyytiälä for two different cutoff diameters. The results showed for both CPC pairs clear WCPC / CPC ratios over 1 during a nucleation event, indicating more hygroscopic compounds participating in formation and initial growth especially at the smaller sizes. For the larger cut-off size CPC pair, the hygroscopicity was not so strong, indicating fewer hygroscopic compounds participating in the growth of the particles.

Combining the work of Kulmala et al. (2007) and Kuang et al. (2012a), our aim in this study is to construct and verify the performance of a nano- $\mathrm{CPCb}$ that will be used as a detector in an SMPS (scanning mobility particle sizer) system. As a whole, this SMPS system consists of an aerosol neutralizer, a nano-DMA (differential mobility analyser), and the nano$\mathrm{CPCb}$ which itself consists of four ultrafine CPCs optimized for the detection of sub- $3 \mathrm{~nm}$ aerosols. In this study, the CPCs of the nano- $\mathrm{CPCb}$ are characterized with mobility classified particles of diverse composition. By doing so, the strong dependence of CPC activation on particle size and charge below $3 \mathrm{~nm}$ (Winkler et al., 2008; Iida et al., 2009; Kuang et al., 2012b; Kangasluoma et al., 2013) is accounted for and any measured differences in CPC response are then attributed solely to the composition-specific interactions between the particle and the various working fluids. Two of the CPCs use diethylene glycol as a working fluid: a laminar type diethylene glycol CPC (DEG CPC, Iida et al., 2009; Kuang et al., 2012b) and a mixing type Airmodus A09 particle size magnifier (PSM) (Vanhanen et al., 2011). The other two CPCs are a modified laminar type TSI 3025A and a modified laminar type TSI 3786 using the working fluids butanol and water, respectively. The PSM and DEG CPC were already shown to be suitable for detecting sub-2 nm clusters (Iida et al., 2009; Kuang et al., 2012b; Kangasluoma et al., 2013; Wimmer et al., 2013), which makes them the best available reference detectors for our instrument. The $3025 \mathrm{~A}$ and the 3786 have also been modified for the detection of sub- $2 \mathrm{~nm}$ clusters (e.g. Sipila et al. (2009) and Kuang et al. (2012b) for 3025A, and Kulmala et al. (2007) for 3786); however, extensive composition dependent studies have been lacking. To maximize the cluster detection using the $3025 \mathrm{~A}$, the saturator temperature was increased to $40^{\circ} \mathrm{C}$, the optics temperature was increased to $42^{\circ} \mathrm{C}$, and the condenser temperature remained at $10^{\circ} \mathrm{C}$. For the 3786 we made the following changes: the saturator temperature was decreased to $5^{\circ} \mathrm{C}$, the growth tube temperature was increased to $78^{\circ} \mathrm{C}$, and the optics temperature was increased to $78^{\circ} \mathrm{C}$, resulting in an operating temperature difference of $73^{\circ} \mathrm{C}$ (several degrees higher than for the WCPC reported in Mordas et al. (2008). The list of CPCs and corresponding operating conditions are listed in Table 1.

To widen the knowledge about working fluid dependent activation for different test aerosols we used aerosol generated from tetraheptyl ammonium bromide (THABr) (Ude and de la Mora, 2005), ammonium sulfate, sodium chloride, tungsten oxide, candle flame products, sucrose, and limonene ozonolysis products and measured their respective cut-off diameters for each of the CPCs comprising the $\mathrm{CPCb}$. The test aerosols and their generation methods are listed in Table 2. Although the composition of the initial sample material is known, the composition of the resulting aerosol will not be always identical to the bulk starting material. For that reason the exact chemical composition as determined through mass spectrometry is vital for sub- $2 \mathrm{~nm}$ CPC calibration studies. The chemical composition of the sub- $2 \mathrm{~nm}$ test aerosol generated from ammonium sulfate, sodium chloride and tungsten oxide was already characterized and presented in our previous study (Kangasluoma et al., 2013). The composition of the test aerosol generated from candle flame products, 
Table 1. List of CPCs used in the nano- $\mathrm{CPCb}$ and their operating conditions and detector CPCs.

\begin{tabular}{lrrrrrl}
\hline CPC & $\begin{array}{r}\text { Saturator } \\
{\left[{ }^{\circ} \mathrm{C}\right]}\end{array}$ & $\begin{array}{r}\text { Condenser } \\
{\left[{ }^{\circ} \mathrm{C}\right]}\end{array}$ & $\begin{array}{r}\text { Optics } \\
{\left[{ }^{\circ} \mathrm{C}\right]}\end{array}$ & $\begin{array}{r}\text { Inlet } \\
{\left[{ }^{\circ} \mathrm{C}\right]}\end{array}$ & $\begin{array}{r}\text { Inlet flow } \\
\text { rate }[\mathrm{Lpm}]\end{array}$ & $\begin{array}{l}\text { Detector } \\
\mathrm{CPC}\end{array}$ \\
\hline DEG-CPC & 60 & 10 & & & 1.5 & 3010 \\
PSM & 78 & 5 & & 15 & 2.5 & 3772 \\
$3025 \mathrm{~A}$ & 40 & 10 & 42 & & 1.5 & \\
3786 & 5 & 78 & 78 & & 0.6 & \\
\hline
\end{tabular}

sucrose and limonene ozonolysis products, as far as resolvable, will be characterized in this study. By knowing the chemical composition of the aerosol used, we show that the response of the four different CPCs is working fluid dependent for different test aerosols. Last, we aim to generate internally mixed aerosol by nucleating ammonium sulfate on tungsten oxide seed particles to see how the activation of the internally mixed particles varies when changing the mixing ratios of the initial aerosols.

\section{Experimental}

The calibration setup, which is presented in Fig. 1, followed a conventional CPC calibration setup for sub- $2 \mathrm{~nm}$ aerosol with the following components: aerosol generator, ${ }^{241} \mathrm{Am}$ radioactive charger, a high resolution DMA in a closed sheath air loop, the nano-CPCb with total aerosol flow of $6.1 \mathrm{Lpm}$ (litre per minute), and a TSI electrometer with an inlet flow rate of $2 \mathrm{Lpm}$. The total inlet flow of the counters was $8.1 \mathrm{Lpm}$, so by having a small electrometer inlet flow, we did not have to dilute the sample flow and we were able to draw the sample flow completely from the DMA. We used a tube furnace and a water bath cooler to generate and then nucleate ammonium sulfate and sodium chloride aerosol, and a hot wire generator (Peineke et al., 2006) to produce tungsten oxide particles. For these three substances we used a Herrmann type high resolution DMA (Herrmann et al., 2000) with detailed chemical characterization described in Kangasluoma et al. (2013). Briefly, in the negative mode (negatively charged aerosol) the chemical composition of generated ammonium sulfate particles is governed by the series $\left(\mathrm{HSO}_{4}\right)_{x}\left(\mathrm{NH}_{3}\right)_{y} \mathrm{SO}_{4}-$ and $\left(\mathrm{HSO}_{4}\right)_{x}\left(\mathrm{NH}_{3}\right)_{y} \mathrm{H}_{2} \mathrm{SO}_{4}+$, the sodium chloride particles by the series $(\mathrm{NaCl})_{x}\left(\mathrm{C}_{4} \mathrm{H}_{10} \mathrm{O}_{3}\right)_{0-2} \mathrm{Cl}-$ and $(\mathrm{NaCl})_{x}\left(\mathrm{C}_{4} \mathrm{H}_{10} \mathrm{O}_{3}\right)_{0-6} \mathrm{Na}+$, and the tungsten oxide particles by the series $\mathrm{W}_{x} \mathrm{O}_{y} \mathrm{H}_{z}\left(\mathrm{C}_{4} \mathrm{H}_{8} \mathrm{O}_{2}\right)_{0-2}-$ with $x / y \approx 1 / 3$ for tungsten oxide. For these three samples, in negative mode when the sample concentration is high enough, there are no charger-generated ions present due to complete charge transfer to the sample clusters, which allows unambiguous sampling of the smallest negative clusters down to $1 \mathrm{~nm}$, the composition of which is confirmed by the APi-TOF. The charge transfer is not complete in the positive mode, probably due to charger generated ions' higher proton

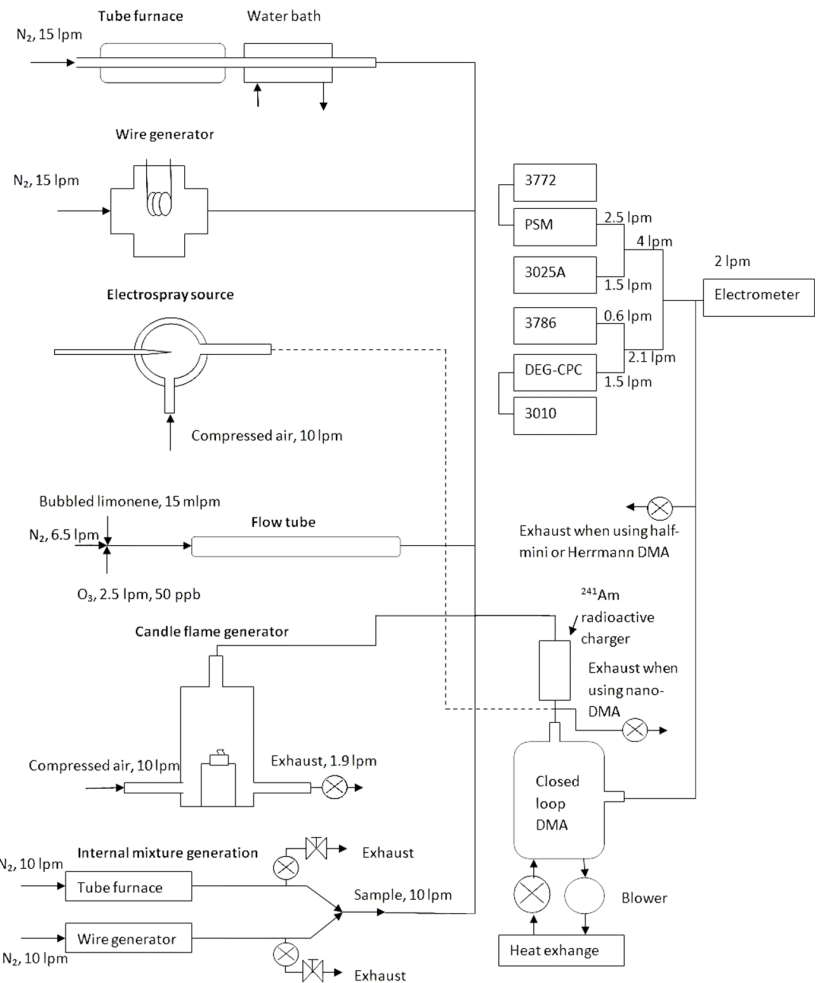

Fig. 1. The upper panel shows the general schematic of the calibration setup used. The lower panel shows the generation setup for the internally mixed aerosol.

affinity compared to the sample clusters. All samples were generated in both polarities to study the potential differences in activation for oppositely charged particles. The Herrmann DMA mobility classification was calibrated after each experiment with $\mathrm{THABr}$ positive monomer, which was the only sample generated only in positive mode.

For the test aerosol generated from the sucrose, candle flame products and limonene ozonolysis products, mobility classification was achieved with a TSI nano-DMA (Chen et al., 1998; Jiang et al., 2011a) for size classification, operating at an aerosol to sheath flow rate ratio of $8.1: 25$. The reason for this was that, when running the Herrmann DMA with very high sheath air flows, the sheath air gets to a higher pressure than ambient pressure which leads to a higher pressure at the inlet of the DMA when compared to the nano-DMA. 
Table 2. List of substances, generation methods, carrier gases, and DMAs used in this study, and literature references to the methods.

\begin{tabular}{|c|c|c|c|c|}
\hline Substance & Method & Carrier gas & DMA & Reference \\
\hline Ammonium sulfate & Tube furnace & $\mathrm{N}_{2}$ & Herrmann & Kangasluoma et al. (2013) \\
\hline Sodium chloride & Tube furnace & $\mathrm{N}_{2}$ & Herrmann & Kangasluoma et al. (2013) \\
\hline Tungsten oxide & Hot wire generator & $\mathrm{N}_{2}$ & Herrmann & Peineke et al. (2006) \\
\hline Sucrose & Electrospray & Compressed air & nDMA & Chen et al. (1995) \\
\hline Limonene ozonolysis products & Flow tube & $\mathrm{N}_{2}$ & nDMA & \\
\hline Candle flame products & Candle chamber & Compressed air & nDMA & Kupc et al. (2013) \\
\hline THABr & Electrospray & Compressed air & Herrmann & Ude and de la Mora (2005) \\
\hline Mixed aerosol & Tube furnace and hot wire generator & $\mathrm{N}_{2}$ & Half-mini & \\
\hline
\end{tabular}

In the case of the electrospray source we found that the higher pressure at the inlet of the DMA, and therefore around the electrospray needle, leads to a high amount of multiply charged particles. The reason for this is unknown and not further studied here. Sucrose was dissolved in Milli-Q water with a hint of ammonium acetate to make the solution conductive (Chen et al., 1995). The same ${ }^{241}$ Am charger was in this experiment used downstream of the electrospray to reduce the charge of the highly charged aerosol coming from the electrospray. To keep the electrospray needle at ambient pressure, the CPCs and the electrometer were used to draw the sample flow from the nano-DMA. Upstream of the electrospray we had a compressed air line with a $\mathrm{T}$ cross in the line pushing a sufficient amount of dry air to the electrospray, so that there was excess flow all the time to prevent the ambient air from getting in and increasing the relative humidity of the sample. As shown in our previous study (Kangasluoma et al., 2013), changes in the relative humidity can significantly alter the detection efficiency, and therefore all experiments conducted in this study are in close to zero relative humidity.

The candle generator, similar to the one used by Kupc et al. (2013), was a $5 \mathrm{~cm}$ radius and $30 \mathrm{~cm}$ tall metal cylinder with two inlets close to the bottom of the cylinder and one outlet at the top face of the cylinder. A candle was placed at the bottom of the cylinder. The chamber was charged with excess flow since there was no bottom plate in the cylinder; this enabled us in a convenient way to monitor the candle flame. To keep the candle flame at ambient pressure, the sample flow was drawn by the CPCs, which is why we used the nano-DMA. The total flow of the detectors was 8.1 Lpm and we pumped into the chamber about $10 \mathrm{Lpm}$ of compressed air from one inlet and let the exhaust go out from the other inlet.

The limonene ozonolysis was carried out in a $4.7 \mathrm{~cm}$ inner diameter and $205 \mathrm{~cm}$ long flow tube made of borosilicate glass, which we did not want to pressurize and therefore the nano-DMA was used for mobility classification. Ozone was supplied to the tube at a concentration of $50 \mathrm{ppb}$ (parts per billion) and a flow rate of $2.5 \mathrm{Lpm}$, while limonene was bubbled with cryo-nitrogen at $15 \mathrm{mLpm}$ (millilitres per minute). In addition, we had $6 \mathrm{Lpm}$ cryo-nitrogen as carrier flow, giving a residence time of about $36 \mathrm{~s}$ in the flow tube. These conditions yielded a stable aerosol distribution in the size range between 1 and $10 \mathrm{~nm}$.

To generate internally mixed aerosol, we built a setup where the flows through the tube furnace and the hot wire generator were mixed just upstream of the water bath cooler. We kept the flow through both of the two generators constant at $10 \mathrm{Lpm}$ throughout the experiment to keep the aerosol generation and composition stable. We also kept the total mixed aerosol flow entering the cooler constant at $10 \mathrm{Lpm}$ by adjusting the excess flows after the generators. The experiments were run at the following flow rate settings that were selected from the $10 \mathrm{Lpm}$ and $10 \mathrm{Lpm}$ flows of the ammonium sulfate and tungsten oxide generators, respectively: 10 and $0 \mathrm{Lpm}, 8$ and $2 \mathrm{Lpm}, 6$ and $4 \mathrm{Lpm}$ and so on. The resulting excess flows, in order to maintain a final flow rate of $10 \mathrm{Lpm}$ through the cooler, were sent through exhaust lines. After the cooler the mixed aerosol was charged and then size classified with a half-mini high resolution DMA (Jiang et al., 2011a; de la Mora and Kozlowski, 2013). To monitor the mixing state and the composition of the aerosol, the precise mass distribution of the aerosol was measured with the Api-TOF, in parallel with the nano-CPCb and the electrometer. The APi-TOF can draw the sample directly at atmospheric pressure, which makes it a well suited mass spectrometer to be used in parallel with CPCs. In the APi-TOF, the pressure is pumped down to $10^{-6}$ mbar in four stages, where in the final chamber the time of flight of the charged ions is measured, yielding the $m / z$ ratio. The mass resolution, that is FWHM of a given peak divided by the mass of the cluster, of the APi-TOF is about 5000, which is accurate enough to resolve the mass defect of the clusters. By combining the information of the isotopic patterns, mass defect and a reasonable guess of the probable cluster composition, one can solve the exact molecular formula of a cluster (Junninen et al., 2010; Kangasluoma et al., 2013). In all of the experiments the sample was led to the CPCs with three T pieces after the DMA, the first split was for the electrometer and the CPCs, the second and third ones to split the sample flow to all the CPCs. To correct for the possible unequal penetration efficiencies we ran an experiment with tungsten oxide and sampled only with 


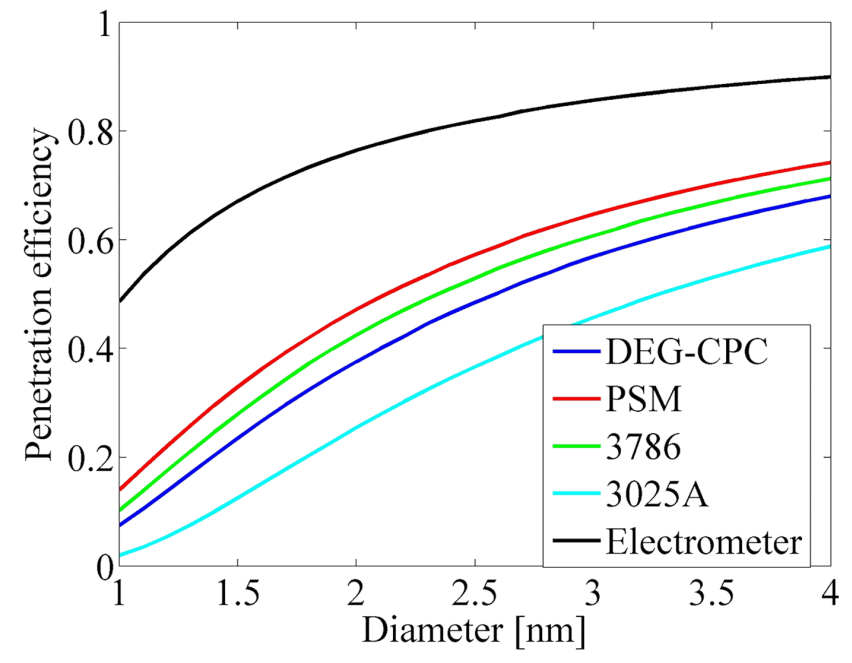

Fig. 2. The estimated penetration efficiencies of the sampling lines.

the electrometer and one CPC at a time in parallel to get the "true" activation efficiency. This could then be compared to the results with the sampling line and scale the obtained detection efficiencies (the product of transport efficiencies and activation efficiencies) to the true activation efficiencies. The corrections used for the line penetration are plotted in Fig. 2.

\section{Results and discussion}

\subsection{Chemical composition of sucrose, candle flame and limonene ozonolysis aerosols}

We found that most of the negatively charged candle flame aerosol signal in the mass spectrometer consisted of sodium nitrate ion pairs where at least one of the nitrate's oxygen has been replaced by sulfur (Fig. 3, bottom). The ion pair could have been $\mathrm{NaNO}_{3}, \mathrm{NaNO}_{2} \mathrm{~S}$, $\mathrm{NaNOS}_{2}$ or $\mathrm{NaNS}_{2}$, which therefore forms a series of $\mathrm{Na}_{x}\left(\mathrm{NO}_{3}\right)_{y}\left(\mathrm{NO}_{2} \mathrm{~S}\right)_{z}\left(\mathrm{NOS}_{2}\right)_{i}\left(\mathrm{NS}_{2}\right)_{j} \mathrm{NO}_{3}-$, where $x=y+$ $z+i+j$. In Fig. 3 the indicated cluster compositions are given only with ion pairs $\mathrm{NaNO}_{3}$ and $\mathrm{NaNO}_{2} \mathrm{~S}$, since from (unit) mass we cannot distinguish, for example, clusters $\left(\mathrm{NaNO}_{2} \mathrm{~S}_{2} \mathrm{NO}_{3}-\right.$ and $\left(\mathrm{NaNO}_{3}\right)\left(\mathrm{NaNOS}_{2}\right) \mathrm{NO}_{3}-$ which have the same unit mass. However, the isotopic patterns of the clusters suggest that the clusters are more sulfated, e.g. might contain ion pairs $\mathrm{NaNOS}_{2}$ or $\mathrm{NaNS}_{2}$. The composition of the positively charged candle flame aerosol was not possible to resolve, as the charger-generated ions overlapped with the sample below $1.5 \mathrm{~nm}$ diameter in size. This is because the charge transfer to the sample from the charger ions was not complete, which is probably due to the higher proton affinity of the charger ions compared to the sample. Thus the identification of the larger clusters gets very difficult if there are no hints from the smallest clusters of what the molecules forming the cluster series could be. When added that proper

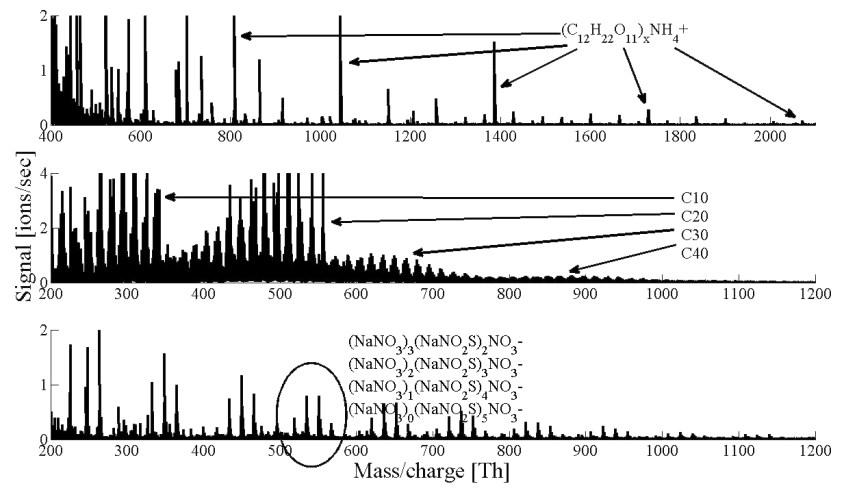

Fig. 3. Mass spectra of positive sucrose (top), negative limonene ozonolysis products (middle) and negative candle flame products (bottom). A more extensive description of the clusters is given in the text.

mass calibration is very difficult with no small known clusters, the cluster identification gets almost impossible in the positive polarity mode.

To identify the composition of the aerosol coming out from the electrospray when spraying sucrose, we led the sample straight from the electrospray to the APi-TOF to maximize the signal without prior mobility classification. A similar procedure was followed when characterizing the limonene ozonolysis products and candle flame products. The APi-TOF confirmed that electrospray generated positively charged sucrose, which was the only sample of these three that gave a clear structure for positively charged aerosol, was composed of oligomeric sucrose molecules and a charged additional molecule (Fig. 3, top). The only identified charge carrier was $\mathrm{NH}_{4}+$, with some unidentified charge carriers with masses of 124,180 and 231. An example series was $\left(\mathrm{C}_{12} \mathrm{H}_{22} \mathrm{O}_{11}\right)_{x} \mathrm{NH}_{4}+$. In addition to this we found doubly charged clusters, which were identical to the singly charged but with a second charge given by an additional charge carrier. The charge carriers in doubly charged clusters were almost always identical, i.e. the signal of doubly charged clusters that had identical charge carriers of mass 231 were significantly higher than a cluster with charge carriers of 231 and 124, or 231 and 180. In addition to these clusters, there were some unidentified doubly charged clusters, which had an unidentified charge carrier. The unidentified clusters also formed a series that grew by one sucrose molecule. The fact that multiply charged clusters were found in the spectra means increased uncertainties for determining the corresponding size-dependent detection efficiencies. The charger-generated ions were also present below $1.5 \mathrm{~nm}$, so keeping these in mind we can still concentrate on the ratio of the $3786 / 3025 \mathrm{~A}$ detection efficiencies, which is the quantity of interest because the sample is still the same for both CPCs. The negatively charged sucrose yielded such a low signal that we were not able to resolve the chemical composition. 
The reaction of limonene and ozone yielded a mass spectrum with many organic peaks, where four bands of signals indicative of oxidized organics can be distinguished from the mass spectrum (Fig. 3, middle). Bands similar to the two smallest (lowest $\mathrm{m} / z$ ) of these were also observed in chamber experiments, where ozonolysis of $\alpha$-pinene was conducted (Ehn et al., 2012). The ozonolysis of $\alpha$-pinene yielded cluster groups that had approximately 10 or 20 carbon atoms in each cluster or molecule. Ehn et al. (2012) reported a $\mathrm{C} / \mathrm{H}$ (carbon/hydrogen) ratio below one and a $\mathrm{C} / \mathrm{O}$ (carbon / oxygen) ratio between 0.7 and 1.3 for the clusters. The clusters are ionized by clustering with nitrate or sulfate ion. These oxidized organics have been already observed from the Hyytiälä measurement station in the boreal forest (Ehn et al., 2010), where the measured cluster structure, similar to that observed in the chamber experiments of Ehn et al. (2012), hints that they are also products of $\alpha$-pinene ozonolysis. While we were not able to identify every single cluster, these C10, C20, C30 and C40 bands were clearly visible from the mass spectrum. From these similarities to the field and chamber results of ozonolysis of $\alpha$-pinene, we can treat these flow tube generated clusters as ambient-relevant organic sub- $2 \mathrm{~nm}$ CPC calibration ions. The positive sample was left unidentified because it did not show any clear patterns or clear cluster series from where the identification could be started.

\subsection{Detection efficiencies, $3786 / 3025 \mathrm{~A}$ ratio and positive vs. negative sample comparison}

For the interpretation of potential ambient measurements, we are interested in the size dependent detection efficiency ratio of the water and butanol CPCs (3786 and 3025A), as it provides indirect information about the size resolved chemical composition of the ambient aerosol; e.g. the degree to which the aerosol is water-soluble versus organic-soluble. In this section we will show how the ratio behaves as a function of chemical composition, particle size, and particle polarity, which can be then potentially used to interpret ambient measurements of aerosol with unknown composition. In addition to the water and butanol CPCs, we also characterized two diethylene glycol CPCs, providing a chemically different working fluid to examine the interactions between particle and condensing vapor. Based on the activation behaviour for the three working fluids, we can divide the sample into three groups which are given below.

Ammonium sulfate and sodium chloride are detected better with the 3786 (water) than the 3025A (butanol) (Fig. 4), yielding the activation efficiency ratio of $3786 / 3025 \mathrm{~A}$ bigger than one (Fig. 5). This is most probably due to hygroscopicity of the salts and is in line with previous experiments (Liu et al., 2006). The 3786/3025A ratio shows an increasing trend with decreasing particle size, and after showing peak value decreases to zero. For the negatively charged ammonium sulfate and sodium chloride the $3786 / 3025 \mathrm{~A}$ ratio peaked at 2.6 and 1.5 , respectively, and for the positively charged aerosol

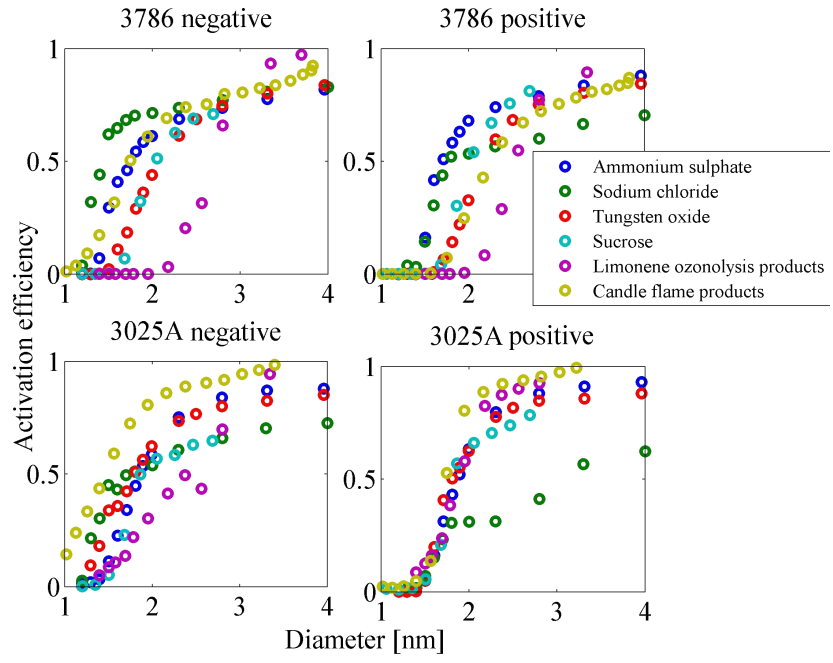

Fig. 4. Detection efficiency of the $3025 \mathrm{~A}$ and 3786 for all generated test aerosols.

the ratio of ammonium sulfate peaked at 3.2 and sodium chloride at 2.9 before the sampling was disturbed by the presence of charger-generated ions. The observed trends in the $3786 / 3025 \mathrm{~A}$ ratio are explained in the negative polarity by the water CPC's ability to activate the smallest clusters, except the smallest sampled size, and on the other hand the effect fading away when sampling big enough clusters. For positive polarity the sample composition changes from salts to organic contaminants when sampling the smallest clusters. In previous studies it has been found that these salts are activated with reasonably high efficiency in the water and DEG-based CPCs (Kulmala et al., 2007; Kangasluoma et al., 2013). In positive mode sodium chloride shows significantly lower activation efficiency plateau values than any other of the samples. As this is observed only with the positive sodium chloride above $1.8 \mathrm{~nm}$ with all CPCs, we assume that this discrepancy is related to the test aerosol. This leads to slightly higher values in the $3786 / 3025 \mathrm{~A}$ ratio for positive sodium chloride above $2 \mathrm{~nm}$. In positive polarity, the charger-generated ions are overlapping with the samples below $1.5 \mathrm{~nm}$, which results in worse detection than negative samples below $1.5 \mathrm{~nm}$ for all working fluids, as the chargergenerated ions are detected worse than ammonium sulfate or sodium chloride.

Negative tungsten oxide, negative candle generated aerosol and sucrose with both polarities showed the opposite activation behaviour than ammonium sulfate and sodium chloride: the 3025A (butanol) detected them better than the 3786 (water), resulting in the $3786 / 3025 \mathrm{~A}$ ratio being below unity across all sizes. However, they are detected better with DEG-based CPCs than with the 3025A. The negative candle flame products were activated with the DEG-based CPCs significantly better than the other substances, which shows DEG working fluid preference to sodium, sulfur or nitrate based 


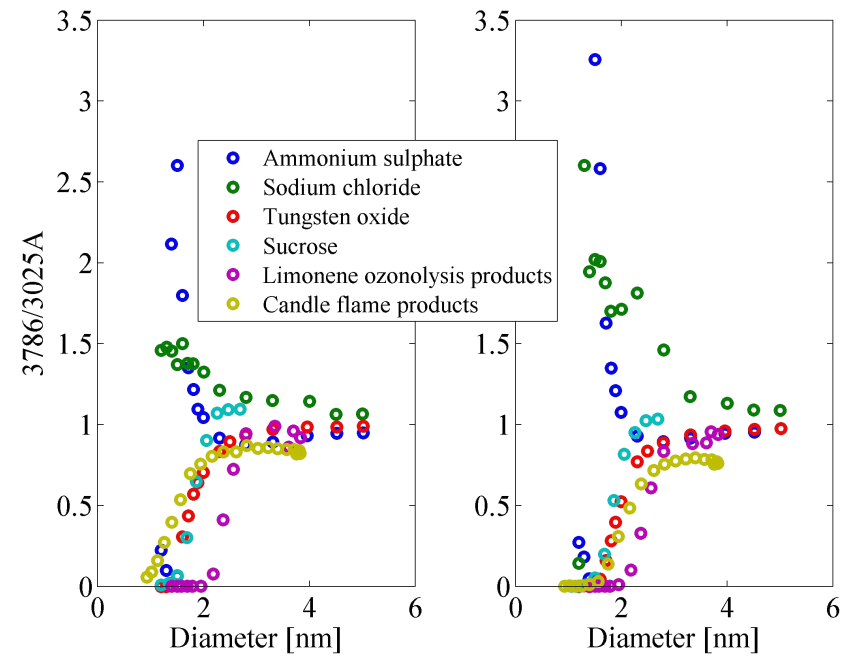

Fig. 5. Ratio of the detection efficiency 3786/3025A for all generated aerosols, left panel shows the negative test aerosol and right panel shows the positive test aerosol.

compounds (Fig. 6), which is already observed with sodium chloride and ammonium sulfate. The positive tungsten oxide and especially the candle generated aerosol, similar to positive $\mathrm{NaCl}$ and ammonium sulfate, are detected worse in positive than negative mode due to organic contamination below $1.5 \mathrm{~nm}$ in the positive mode. Sucrose showed about equal activation efficiency for both polarities across all working fluids, which hints that the positive and negative samples are potentially similar in chemical composition.

The last two substances, negative limonene ozonolysis products and positively charged $\mathrm{THABr}$, were clearly detected the best with the $3025 \mathrm{~A}$. For negative limonene, the $\mathrm{d} 10$ (the diameter where activation efficiency is $10 \%$ ) for the $3025 \mathrm{~A}$ was $1.55 \mathrm{~nm}$ whereas for the other CPCs it was $>2 \mathrm{~nm}$. This is not seen in Table 3 which lists only the d50 diameters, the diameter where the activation efficiency is $50 \%$. THABr shows similar activation behavior as both positively and negatively charged limonene (Table 3), in general very low activation efficiencies compared to other substances with highest activation using butanol. Positive limonene ozonolysis products were detected better than negative ones across all used working fluids.

When looking at DEG-based CPC detection efficiencies, one notes the low detection for limonene (and positive samples, except $\mathrm{THABr}$, that are charger ion contaminated) up to below $2 \mathrm{~nm}$ compared to all other samples, as seen in Table 3 . This is in line with our previous study (Kangasluoma et al., 2013; Wimmer et al., 2013) that concluded that DEG activates sub-2 $\mathrm{nm}$ organics very poorly, which should be kept in mind when sampling with DEG-based CPCs from sites which may contain much organic aerosol.

From the CPCs, the $3025 \mathrm{~A}$ was the most insensitive for chemical composition, the $\mathrm{d} 50$ being $1.8 \pm 0.1 \mathrm{~nm}$ for most

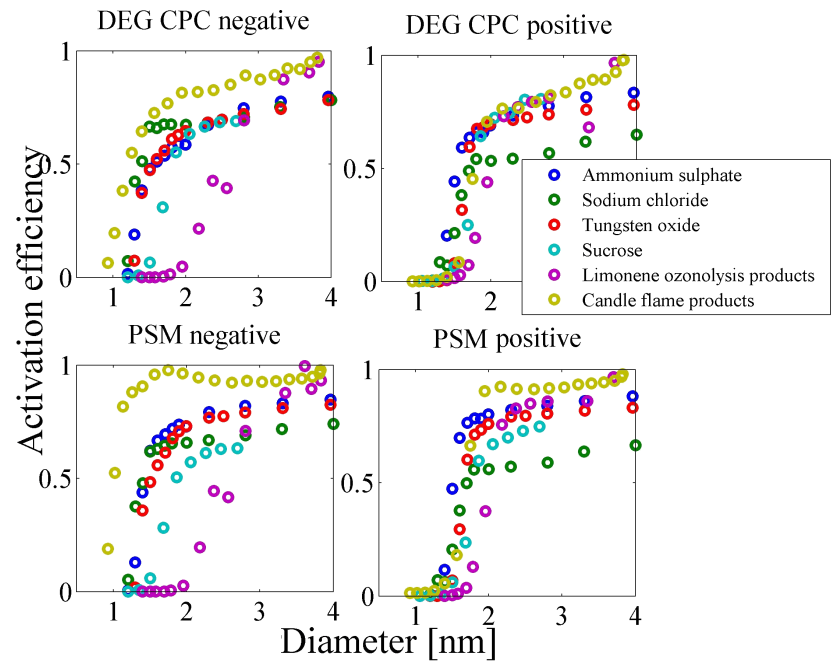

Fig. 6. Detection efficiency of the DEG CPC and PSM for all generated test aerosols.

substances. The 3786 compared to $3025 \mathrm{~A}$ showed clear preference for sodium chloride and ammonium sulfate (water soluble substances) with d50 diameters from 1.4 to $1.8 \mathrm{~nm}$, and from 2.0 to $2.7 \mathrm{~nm}$ for not water soluble substances. The d50 diameters of DEG-based CPCs were at their lowest between 1 and $1.5 \mathrm{~nm}$ for inorganic samples and $>1.7 \mathrm{~nm}$ for partly or completely organic samples.

So far we have shown that the activation efficiency is a clear function of chemical composition at a fixed mobility diameter. Generally, water and DEG activate salts better than butanol, whereas it is the opposite for organics. Tungsten oxide, candle flame and sucrose products are something in between, but butanol activation is still higher than with water. Also we found a slight preference for water activation of positively charged ammonium sulfate and sodium chloride for which we do not know the reason. These results are the basis for developing and applying the nano-CPCb for ambient experiments.

\subsection{Aerosol mixing state and the composition of internally mixed aerosol}

We showed how the activation is a function of composition. However, outside laboratory conditions the sampled aerosol might not (and likely does not) consist of only one well defined substance, but rather is a mixture of different substances. In the second half of this paper we aim to take the first steps into the controlled generation of sub- $2 \mathrm{~nm}$ internally mixed aerosol with a range in composition, and thereby study the effect of the mixing state of the aerosol on the corresponding activation efficiency.

To calculate the mixing state of the aerosol, we first labelled clusters from pure tungsten oxide and ammonium sulfate mass spectra as acquired by the APi-TOF. Then by looking at mass spectra where the two substances were mixed a 
Table 3. Measured d50 values [nm] for the generated particles and activation efficiencies [\%] for the tetraheptyl ammonium bromide (THABr) positive monomer and dimer.

\begin{tabular}{lrrrr}
\hline & DEG-CPC & PSM & $3025 \mathrm{~A}$ & 3786 \\
\hline Ammonium sulfate- & 1.52 & 1.41 & 1.83 & 1.73 \\
Ammonium sulfate+ & 1.52 & 1.49 & 1.84 & 1.67 \\
Sodium chloride- & 1.39 & 1.42 & 1.73 & 1.44 \\
Sodium chloride+ & 1.72 & 1.71 & 3.09 & 1.78 \\
Tungsten oxide- & 1.52 & 1.50 & 1.76 & 2.07 \\
Tungsten oxide+ & 1.65 & 1.65 & 1.77 & 2.16 \\
Sucrose- & 1.83 & 1.86 & 1.87 & 2.04 \\
Sucrose+ & 1.80 & 1.82 & 1.83 & 2.03 \\
Limonene ozonolysis products- & 2.65 & 2.64 & 2.63 & 2.70 \\
Limonene ozonolysis products+ & 1.79 & 1.69 & 1.74 & 2.27 \\
Candle flame products- & 1.22 & 1.02 & 1.47 & 1.75 \\
Candle flame products+ & 1.79 & 1.69 & 1.74 & 2.27 \\
\hline THABr monomer & 0.08 & 0.10 & 0.16 & 0.01 \\
THABr dimer & 0.52 & 0.42 & 3.11 & 0.19 \\
\hline
\end{tabular}

few clusters were found, which were not present in either of the pure sample spectrum. From these we summed the signal intensities corresponding to the pure ammonium sulfate, pure tungsten oxide, and the resulting mixed clusters, $I_{\mathrm{As}}, I_{\mathrm{WOx}}$ and $I_{\mathrm{Mix}}$, respectively, and calculated the mixing ratios, MR, of the mixed clusters of the aerosol as

$\mathrm{MR}_{\mathrm{Mix}}=\frac{I_{\mathrm{Mix}}}{I_{\mathrm{As}}+I_{\mathrm{WOx}}+I_{\mathrm{Mix}}}$.

The mixing ratio is essentially the fraction of the measured signal that is attributed to clusters of mixed composition, which is our trace for the mixing state of the aerosol. The mixing ratio of the aerosol is presented in Table 4 . We found the highest signal for internally mixed clusters when tungsten oxide flow was slightly bigger than ammonium sulfate flow. Internally mixed clusters were detected with low intensity even when we had only one of the flows going into the mixing zone. This might be due to some residual sulfate or tungsten oxide in the cooler which then clustered with the incoming clusters.

At a mobility diameter of $1.3 \mathrm{~nm}$, which was the only size that gave a reasonable signal as measured by the APi-TOF, the tungsten oxide clusters of the

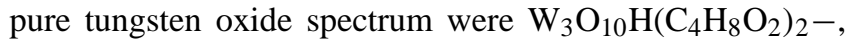
$\mathrm{W}_{4} \mathrm{O}_{15} \mathrm{H}_{2}-, \mathrm{W}_{6} \mathrm{O}_{19} \mathrm{H}-, \mathrm{W}_{6} \mathrm{O}_{15} \mathrm{H}_{(}\left(\mathrm{C}_{4} \mathrm{H}_{8} \mathrm{O}_{2}\right)_{2}-, \mathrm{W}_{7} \mathrm{O}_{22} \mathrm{H}-$ and $\mathrm{W}_{7} \mathrm{O}_{18} \mathrm{H}_{(}\left(\mathrm{C}_{4} \mathrm{H}_{8} \mathrm{O}_{2}\right)_{2}-$ which are all identified in our previous study (Kangasluoma et al., 2013). The internally mixed clusters, which we separate into two groups based on mass, were identified as $\mathrm{W}_{3} \mathrm{O}_{8-10} \mathrm{H}\left(\mathrm{C}_{4} \mathrm{H}_{8} \mathrm{O}_{2}\right)_{2}\left(\mathrm{SO}_{4}\right)_{x}-$ up to $x=5$, which are the lighter clusters with $m / z<1400$. The heavier clusters, with $m / z>1600$, were identified as $\mathrm{W}_{6} \mathrm{O}_{19} \mathrm{HS}_{2} \mathrm{O}_{8}-$ and $\mathrm{W}_{6} \mathrm{O}_{15} \mathrm{H}_{(}\left(\mathrm{C}_{4} \mathrm{H}_{8} \mathrm{O}_{2}\right)_{2} \mathrm{~S}_{2} \mathrm{O}_{8}-$, which are tungsten oxide clusters attached with persulfate. These observed internally mixed clusters suggest that sulfate was clustering with tungsten oxide particles. The signal intensities
Table 4. Calculated fraction of ammonium sulfate and tungsten oxide in the mixing experiment.

\begin{tabular}{lrrr}
\hline Flows & $\begin{array}{r}\text { Tungsten } \\
\text { oxide }\end{array}$ & $\begin{array}{r}\text { Ammonium } \\
\text { sulfate }\end{array}$ & $\begin{array}{r}\text { Mixed } \\
\text { aerosol }\end{array}$ \\
\hline WOx 10 Lpm, As 0 Lpm & 0.86 & 0 & 0.14 \\
WOx 8 Lpm, As 2 Lpm & 0.63 & 0 & 0.37 \\
WOx 6 Lpm, As 4 Lpm & 0.37 & 0.10 & 0.53 \\
WOx 4 Lpm, As 6 Lpm & 0.22 & 0.36 & 0.42 \\
WOx 2 Lpm, As 8 Lpm & 0.07 & 0.77 & 0.16 \\
WOx 0 Lpm, As 10 Lpm & 0.03 & 0.92 & 0.05 \\
\hline
\end{tabular}

of the internally mixed clusters are plotted in Fig. 7 (upper panel). The mass division also shows up in the figure so that lighter clusters appear already at tungsten oxide flows 2 and $4 \mathrm{Lpm}$, whereas the two heavier ones mostly at flows 6 and $8 \mathrm{Lpm}$. This is an interesting observation about the nucleation dynamics that we cannot explain within this study. In this study, it is enough to monitor the mixing state of the aerosol and see how it affects the resulting activation efficiencies of the internally mixed clusters.

For the detection efficiency of the total aerosol, which is here composed of internally and externally mixed aerosol, we found different responses depending on the working fluid as a function of the mixed flow. They are presented in Fig. 7 (lower panel) with thinner lines, where the $x$ axis is the tungsten oxide flow rate. The ammonium sulfate flow rate is then $10 \mathrm{Lpm}$ minus the tungsten oxide flow rate. PSM and DEG CPC detection efficiency show a decreasing trend as a function of tungsten oxide flow rate. The 3025A has a rather constant detection efficiency except at flow rates of 2 and $4 \mathrm{Lpm}$ where the activation efficiency is slightly lower. The 3786 shows decreasing activation efficiency with increasing tungsten oxide flow rate: the total detection efficiency decreases 


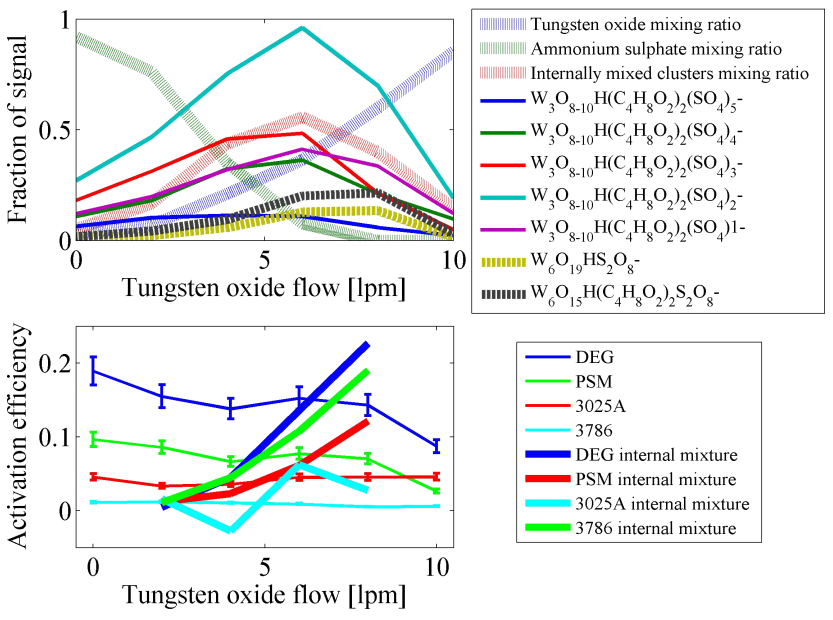

Fig. 7. Upper panel shows the mixing state of the aerosol, dotted lines are fractions of the total given on the left, dashed lines are the heavier clusters and solid lines are lighter clusters with arbitrary unit. The composition changes smoothly from ammonium sulfate to tungsten oxide as a function of flow. Heavier clusters with six tungstens show the highest signal at flow of $8 \mathrm{Lpm}$ whereas the lighter ones show highest signals at flows of 4 and $6 \mathrm{Lpm}$. Lower panel shows the CPC detection efficiencies for the total aerosol and the detection efficiencies for only the internally mixed clusters as a function of tungsten oxide flow. The detection efficiency of the total aerosol shows a peak at a flow of $8 \mathrm{Lpm}$ for PSM, DEG CPC and 3025A. The peak is more visible when the detection efficiency of the internally mixed clusters is extracted. We account this flow dependency to the same signal pattern of the heavier internally mixed clusters.

from 0.012 to 0.006 as tungsten oxide flow rate increases from 0 to $10 \mathrm{Lpm}$. To explain the observed behaviour in the total detection efficiency in the experiment, a deeper look into the mass spectra needs to be taken. Also the detection efficiency of the internally mixed aerosol must be extracted.

Assuming that the detection of the internal mixture can be given by one single value (which is likely a weighed average of all clusters in the spectrum), which represents the activation of all internally mixed clusters, the internal mixture detection efficiencies were calculated as

$$
\begin{array}{r}
\mathrm{MR}_{\mathrm{As}} \cdot \operatorname{Det}_{\mathrm{As}}+\mathrm{MR}_{\mathrm{WOx}} \cdot \operatorname{Det}_{\mathrm{WOx}} \\
+\mathrm{MR}_{\mathrm{Mix}} \cdot \operatorname{Det}_{\mathrm{Mix}}=\operatorname{Det}_{\mathrm{Tot}},
\end{array}
$$

from where the Det $\mathrm{Mix}_{\mathrm{x}}$ is given by

$\operatorname{Det}_{\text {Mix }}=\frac{\text { Det }_{\text {Tot }}-\mathrm{MR}_{\mathrm{As}} \cdot \operatorname{Det}_{\mathrm{As}}-\mathrm{MR}_{\mathrm{WOx}} \cdot \operatorname{Det}_{\mathrm{WOx}}}{\mathrm{MR}_{\mathrm{Mix}}}$,

where Det refers to detection efficiency, MR, calculated from the mass spectra, to mixing ratio, Mix to the internally mixed aerosol, As to ammonium sulfate, WOx to tungsten oxide and Tot to As + WOx + Mix.

Using Eq. (3) the effect of pure clusters to the detection efficiency is subtracted and then normalized back by the fraction of the internally mixed clusters. We only calculated the internal mixture detection efficiencies for tungsten oxide flows of 2-8 Lpm, because the internal mixture detection was normalized by $\mathrm{MR}_{\mathrm{Mix}}$, which should be zero for pure samples. The results are shown in Fig. 7 (lower panel) with thicker lines. For all the CPCs the calculated detection of internally mixed clusters shows an increase with the increasing tungsten oxide flow. Our interpretation of the observation is that the CPCs detect the heavier internally mixed clusters better than the lighter ones, though the clusters are selected with the same mobility. The scattering and negative detection efficiency for 3786 is probably due to quite a low signal in the total detection efficiency, which increases uncertainties. However, based on the trends of the curves and another similar experiment conducted which showed similar activation behaviour, increase as a function of tungsten oxide flow, we conclude that the first attempt to create and monitor the mixing state of a sub- $2 \mathrm{~nm}$ aerosol and interpret the effect of mixing state to the detection efficiency of a CPC was successful.

\section{Conclusions}

In this study we assembled a nano-CPC battery and characterized it in the laboratory with seven different types of aerosol: ammonium sulfate, sodium chloride, tungsten oxide, sucrose, candle flame products, THABr and limonene ozonolysis products. We found that as a function of size the salts, ammonium sulfate and sodium chloride, were detected better with a tuned 3786 (water) than tuned 3025A (butanol), whereas it is the opposite for the rest of the aerosols. The result is a confirmation to use the nano-CPC battery in the field to obtain composition information from mobility-classified ambient aerosol. Another important result is that limonene ozonolysis products are detected very poorly with the diethylene glycol-based DEG CPC and the PSM, with d50 diameter being only $2.6 \mathrm{~nm}$. To explore the possibility of generating internally mixed aerosol we nucleated ammonium sulfate with tungsten oxide and observed internally mixed clusters, where $\mathrm{SO}_{4}$ was clustered with three different tungsten oxide clusters. Finally, by using the APi-TOF, we found that at $1.3 \mathrm{~nm}$ mobility diameter the activation efficiency of the internally mixed clusters changes as a function of mixing state of the internally mixed clusters.

Acknowledgements. This work was partly funded by the European Research Council (ATMNUCLE, 227463), Academy of Finland (Center of Excellence Program projects 1118615 and 139656), Nordic Center for Excellence (CRAICC), European Commission seventh Framework program (ACTRIS, contract no. 262254; PEGASOS, contract no. 265148) and Maj and Tor Nessling Foundation. Also we want to thank the tofTools team for providing 
tools for mass spectrometry analysis and M. Attoui for providing the wire generator and electrospray source.

Edited by: W. Maenhaut

\section{References}

Aalto, P., Hameri, K., Becker, E., Weber, R., Salm, J., Makela, J. M., Hoell, C., O’Dowd, C. D., Karlsson, H., Hansson, H. C., Vakeva, M., Koponen, I. K., Buzorius, G., and Kulmala, M.: Physical characterization of aerosol particles during nucleation events, Tellus B, 53, 344-358, doi:10.1034/j.1600-0889.2001.530403.x, 2001.

Berndt, T., Jokinen, T., Mauldin, R. L., Petaja, T., Herrmann, H., Junninen, H., Paasonen, P., Worsnop, D. R., and Sipila, M.: Gas-phase ozonolysis of selected olefins: the yield of stabilized Criegee intermediate and the reactivity toward $\mathrm{SO}_{2}$, J. Phys. Chem. Lett., 3, 2892-2896, doi:10.1021/Jz301158u, 2012.

Bzdek, B. R., Zordan, C. A., Luther, G. W., and Johnston, M. V.: Nanoparticle chemical composition during new particle formation, Aerosol. Sci. Tech., 45, 1041-1048, doi:10.1080/02786826.2011.580392, 2011.

Chen, D. R., Pui, D. Y. H., and Kaufman, S. L.: Electrospraying of conducting liquids for monodisperse aerosol generation in the $4 \mathrm{~nm}$ to $1.8 \mu \mathrm{m}$ diameter range, J. Aerosol. Sci., 26, 963-977, doi:10.1016/0021-8502(95)00027-A, 1995.

Chen, D. R., Pui, D. Y. H., Hummes, D., Fissan, H., Quant, F. R., and Sem, G. J.: Design and evaluation of a nanometer aerosol differential mobility analyzer (Nano-DMA), J. Aerosol. Sci., 29, 497-509, doi:10.1016/S0021-8502(97)10018-0, 1998.

de la Mora, J. F. and Kozlowski, J.: Hand-held differential mobility analyzers of high resolution for $1-30 \mathrm{~nm}$ particles: Design and fabrication considerations, J. Aerosol. Sci., 57, 45-53, doi:10.1016/j.jaerosci.2012.10.009, 2013.

Ehn, M., Petäjä, T., Aufmhoff, H., Aalto, P., Hämeri, K., Arnold, F., Laaksonen, A., and Kulmala, M.: Hygroscopic properties of ultrafine aerosol particles in the boreal forest: diurnal variation, solubility and the influence of sulfuric acid, Atmos. Chem. Phys., 7, 211-222, doi:10.5194/acp-7-211-2007, 2007.

Ehn, M., Junninen, H., Petäjä, T., Kurtén, T., Kerminen, V.-M., Schobesberger, S., Manninen, H. E., Ortega, I. K., Vehkamäki, H., Kulmala, M., and Worsnop, D. R.: Composition and temporal behavior of ambient ions in the boreal forest, Atmos. Chem. Phys., 10, 8513-8530, doi:10.5194/acp-10-8513-2010, 2010.

Ehn, M., Kleist, E., Junninen, H., Petäjä, T., Lönn, G., Schobesberger, S., Dal Maso, M., Trimborn, A., Kulmala, M., Worsnop, D. R., Wahner, A., Wildt, J., and Mentel, Th. F.: Gas phase formation of extremely oxidized pinene reaction products in chamber and ambient air, Atmos. Chem. Phys., 12, 5113-5127, doi:10.5194/acp-12-5113-2012, 2012.

Herrmann, W., Eichler, T., Bernardo, N., and Fernández de la Mora, J.: Turbulent transition arises at reynolds number 35,000 in a short vienna type DMA with a large laminarization inlet. Abstract AAAR Conference, 15B5, 2000.

Iida, K., Stolzenburg, M. R., and McMurry, P. H.: Effect of working fluid on Sub- $2 \mathrm{~nm}$ particle detection with a laminar flow ultrafine condensation particle counter, Aerosol. Sci. Tech., 43, 8196, doi:10.1080/02786820802488194, 2009.
IPCC: Summary for Policymakers. Climate Change 2007: The physical science basis: contribution of working group I to the fourth assessment report of the intergovernmental panel on climate change, edited by: Solomon, S., Qin, D., Manning, M., Chen, Z., Marquis, M., Averyt, K. B., Tignor, M., and Miller, H. L., Cambridge University Press, Cambridge, United Kingdom and New York, NY, USA, 2007.

Jiang, J. K., Attoui, M., Heim, M., Brunelli, N. A., McMurry, P. H., Kasper, G., Flagan, R. C., Giapis, K., and Mouret, G.: Transfer functions and penetrations of five differential mobility analyzers for sub-2 nm particle classification, Aerosol. Sci. Tech., 45, 480 492, doi:10.1080/02786826.2010.546819, 2011a.

Jiang, J. K., Zhao, J., Chen, M. D., Eisele, F. L., Scheckman, J., Williams, B. J., Kuang, C. A., and McMurry, P. H.: First measurements of neutral atmospheric cluster and 1-2 nm particle number size distributions during nucleation events, Aerosol. Sci. Tech., 45, ii-v, doi:10.1080/02786826.2010.546817, 2011 b.

Jokinen, T., Sipilä, M., Junninen, H., Ehn, M., Lönn, G., Hakala, J., Petäjä, T., Mauldin III, R. L., Kulmala, M., and Worsnop, D. R.: Atmospheric sulphuric acid and neutral cluster measurements using CI-APi-TOF, Atmos. Chem. Phys., 12, 4117-4125, doi:10.5194/acp-12-4117-2012, 2012.

Junninen, H., Ehn, M., Petäjä, T., Luosujärvi, L., Kotiaho, T., Kostiainen, R., Rohner, U., Gonin, M., Fuhrer, K., Kulmala, M., and Worsnop, D. R.: A high-resolution mass spectrometer to measure atmospheric ion composition, Atmos. Meas. Tech., 3, 10391053, doi:10.5194/amt-3-1039-2010, 2010.

Kangasluoma, J., Junninen, H., Lehtipalo, K., Mikkila, J., Vanhanen, J., Attoui, M., Sipila, M., Worsnop, D., Kulmala, M., and Petaja, T.: Remarks on ion generation for CPC detection efficiency studies in sub-3-nm size range, Aerosol. Sci. Tech., 47, 556-563, doi:10.1080/02786826.2013.773393, 2013.

Keskinen, H., Virtanen, A., Joutsensaari, J., Tsagkogeorgas, G., Duplissy, J., Schobesberger, S., Gysel, M., Riccobono, F., Slowik, J. G., Bianchi, F., Yli-Juuti, T., Lehtipalo, K., Rondo, L., Breitenlechner, M., Kupc, A., Almeida, J., Amorim, A., Dunne, E. M., Downard, A. J., Ehrhart, S., Franchin, A., Kajos, M. K., Kirkby, J., Kürten, A., Nieminen, T., Makhmutov, V., Mathot, S., Miettinen, P., Onnela, A., Petäjä, T., Praplan, A., Santos, F. D., Schallhart, S., Sipilä, M., Stozhkov, Y., Tomé, A., Vaattovaara, P., Wimmer, D., Prevot, A., Dommen, J., Donahue, N. M., Flagan, R.C., Weingartner, E., Viisanen, Y., Riipinen, I., Hansel, A., Curtius, J., Kulmala, M., Worsnop, D. R., Baltensperger, U., Wex, H., Stratmann, F., and Laaksonen, A.: Evolution of particle composition in CLOUD nucleation experiments, Atmos. Chem. Phys., 13, 5587-5600, doi:10.5194/acp-13-5587-2013, 2013.

Kirkby, J., Curtius, J., Almeida, J., Dunne, E., Duplissy, J., Ehrhart, S., Franchin, A., Gagne, S., Ickes, L., Kurten, A., Kupc, A., Metzger, A., Riccobono, F., Rondo, L., Schobesberger, S., Tsagkogeorgas, G., Wimmer, D., Amorim, A., Bianchi, F., Breitenlechner, M., David, A., Dommen, J., Downard, A., Ehn, M., Flagan, R. C., Haider, S., Hansel, A., Hauser, D., Jud, W., Junninen, H., Kreissl, F., Kvashin, A., Laaksonen, A., Lehtipalo, K., Lima, J., Lovejoy, E. R., Makhmutov, V., Mathot, S., Mikkila, J., Minginette, P., Mogo, S., Nieminen, T., Onnela, A., Pereira, P., Petaja, T., Schnitzhofer, R., Seinfeld, J. H., Sipila, M., Stozhkov, Y., Stratmann, F., Tome, A., Vanhanen, J., Viisanen, Y., Vrtala, A., Wagner, P. E., Walther, H., Weingartner, E., Wex, H., Winkler, P. M., Carslaw, K. S., Worsnop, D. R., Baltensperger, U., 
and Kulmala, M.: Role of sulphuric acid, ammonia and galactic cosmic rays in atmospheric aerosol nucleation, Nature, 476, 429-477, doi:10.1038/Nature10343, 2011.

Kuang, C., McMurry, P. H., McCormick, A. V., and Eisele, F. L.: Dependence of nucleation rates on sulfuric acid vapor concentration in diverse atmospheric locations, J. Geophys. Res.-Atmos., 113, D10209, doi:10.1029/2007jd009253, 2008.

Kuang, C., Chen, M., Zhao, J., Smith, J., McMurry, P. H., and Wang, J.: Size and time-resolved growth rate measurements of 1 to $5 \mathrm{~nm}$ freshly formed atmospheric nuclei, Atmos. Chem. Phys., 12, 3573-3589, doi:10.5194/acp-12-3573-2012, 2012a.

Kuang, C. A., Chen, M. D., McMurry, P. H., and Wang, J.: Modification of laminar flow ultrafine condensation particle counters for the enhanced detection of $1 \mathrm{~nm}$ condensation nuclei, Aerosol. Sci. Tech., 46, 309-315, doi:10.1080/02786826.2011.626815, 2012b.

Kulmala, M., Mordas, G., Petaja, T., Gronholm, T., Aalto, P. P., Vehkamaki, H., Hienola, A. I., Herrmann, E., Sipila, M., Riipinen, I., Manninen, H. E., Hameri, K., Stratmann, F., Bilde, M., Winkler, P. M., Birmili, W., and Wagner, P. E.: The condensation particle counter battery (CPCB): A new tool to investigate the activation properties of nanoparticles, J. Aerosol. Sci., 38, 289304, doi:10.1016/j.jaerosci.2006.11.008, 2007.

Kulmala, M., Kontkanen, J., Junninen, H., Lehtipalo, K., Manninen, H. E., Nieminen, T., Petaja, T., Sipila, M., Schobesberger, S., Rantala, P., Franchin, A., Jokinen, T., Jarvinen, E., Aijala, M., Kangasluoma, J., Hakala, J., Aalto, P. P., Paasonen, P., Mikkila, J., Vanhanen, J., Aalto, J., Hakola, H., Makkonen, U., Ruuskanen, T., Mauldin, R. L., Duplissy, J., Vehkamaki, H., Back, J., Kortelainen, A., Riipinen, I., Kurten, T., Johnston, M. V., Smith, J. N., Ehn, M., Mentel, T. F., Lehtinen, K. E. J., Laaksonen, A., Kerminen, V. M., and Worsnop, D. R.: Direct observations of atmospheric aerosol nucleation, Science, 339, 943-946, doi:10.1126/science.1227385, 2013.

Kupc, A., Bischof, O., Tritscher, T., Beeston, M., Krinke, T., and Wagner, P. E.: Laboratory characterization of a new nano-waterbased CPC 3788 and performance comparison to an ultrafine butanol-based CPC 3776, Aerosol Sci. Technol., 47, 183-191, 2013.

Lehtipalo, K., Sipilä, M., Riipinen, I., Nieminen, T., and Kulmala, M.: Analysis of atmospheric neutral and charged molecular clusters in boreal forest using pulse-height CPC, Atmos. Chem. Phys., 9, 4177-4184, doi:10.5194/acp-9-4177-2009, 2009.

Lehtipalo, K., Kulmala, M., Sipilä, M., Petäjä, T., Vana, M., Ceburnis, D., Dupuy, R., and O'Dowd, C.: Nanoparticles in boreal forest and coastal environment: a comparison of observations and implications of the nucleation mechanism, Atmos. Chem. Phys., 10, 7009-7016, doi:10.5194/acp-10-7009-2010, 2010.

Liu, W., Kaufman, S. L., Osmondson, B. L., Sem, G. J., Quant, F. R., and Oberreit, D. R.: Water-based condensation particle counters for environmental monitoring of ultrafine particles, J. Air Waste Manage., 56, 444-455, 2006.

Manninen, H. E., Petaja, T., Asmi, E., Riipinen, I., Nieminen, T., Mikkila, J., Horrak, U., Mirme, A., Mirme, S., Laakso, L., Kerminen, V. M., and Kulmala, M.: Long-term field measurements of charged and neutral clusters using neutral cluster and air ion spectrometer (NAIS), Boreal Environ. Res., 14, 591-605, 2009.

Manninen, H. E., Franchin, A., Schobesberger, S., Hirsikko, A., Hakala, J., Skromulis, A., Kangasluoma, J., Ehn, M., Junninen,
H., Mirme, A., Mirme, S., Sipilä, M., Petäjä, T., Worsnop, D. R., and Kulmala, M.: Characterisation of corona-generated ions used in a Neutral cluster and Air Ion Spectrometer (NAIS), Atmos. Meas. Tech., 4, 2767-2776, doi:10.5194/amt-4-2767-2011, 2011.

Merikanto, J., Spracklen, D. V., Pringle, K. J., and Carslaw, K. S.: Effects of boundary layer particle formation on cloud droplet number and changes in cloud albedo from 1850 to 2000, Atmos. Chem. Phys., 10, 695-705, doi:10.5194/acp-10-695-2010, 2010.

Mordas, G., Sipila, M., and Kulmala, M.: Nanometer particle detection by the condensation particle counter UF-02proto, Aerosol. Sci. Tech., 42, 521-527, doi:10.1080/02786820802220233, 2008.

Peineke, C., Attoui, M. B., and Schmidt-Ott, A.: Using a glowing wire generator for production of charged, uniformly sized nanoparticles at high concentrations, J. Aerosol. Sci., 37, 16511661, doi:10.1016/j.jaerosci.2006.06.006, 2006.

Riipinen, I., Sihto, S.-L., Kulmala, M., Arnold, F., Dal Maso, M., Birmili, W., Saarnio, K., Teinilä, K., Kerminen, V.-M., Laaksonen, A., and Lehtinen, K. E. J.: Connections between atmospheric sulphuric acid and new particle formation during QUEST III-IV campaigns in Heidelberg and Hyytiälä, Atmos. Chem. Phys., 7, 1899-1914, doi:10.5194/acp-7-1899-2007, 2007.

Riipinen, I., Manninen, H. E., Yli-Juuti, T., Boy, M., Sipilä, M., Ehn, M., Junninen, H., Petäjä, T., and Kulmala, M.: Applying the Condensation Particle Counter Battery (CPCB) to study the water-affinity of freshly-formed 2-9 nm particles in boreal forest, Atmos. Chem. Phys., 9, 3317-3330, doi:10.5194/acp-9-33172009, 2009.

Riipinen, I., Yli-Juuti, T., Pierce, J. R., Petaja, T., Worsnop, D. R., Kulmala, M., and Donahue, N. M.: The contribution of organics to atmospheric nanoparticle growth, Nat. Geosci., 5, 453-458, doi:10.1038/Ngeo1499, 2012.

Sakurai, H., Fink, M. A., McMurry, P. H., Mauldin, L., Moore, K. F., Smith, J. N., and Eisele, F. L.: Hygroscopicity and volatility of 4-10 nm particles during summertime atmospheric nucleation events in urban Atlanta, J. Geophys. Res.-Atmos., 110, D22s04, doi:10.1029/2005jd005918, 2005.

Sipila, M., Lehtipalo, K., Attoui, M., Neitola, K., Petaja, T., Aalto, P. P., O'Dowd, C. D., and Kulmala, M.: Laboratory verification of $\mathrm{PH}-\mathrm{CPC}$ 's ability to monitor atmospheric Sub-3 nm clusters, Aerosol. Sci. Tech., 43, 126-135, doi:10.1080/02786820802506227, 2009.

Sipila, M., Berndt, T., Petaja, T., Brus, D., Vanhanen, J., Stratmann, F., Patokoski, J., Mauldin, R. L., Hyvarinen, A. P., Lihavainen, H., and Kulmala, M.: The role of sulfuric acid in atmospheric nucleation, Science, 327, 1243-1246, doi:10.1126/science.1180315, 2010.

Smith, J. N., Barsanti, K. C., Friedli, H. R., Ehn, M., Kulmala, M., Collins, D. R., Scheckman, J. H., Williams, B. J., and McMurry, P. H.: Observations of aminium salts in atmospheric nanoparticles and possible climatic implications, P. Natl. Acad. Sci. USA, 107, 6634-6639, doi:10.1073/pnas.0912127107, 2010.

Ude, S. and de la Mora, J. F.: Molecular monodisperse mobility and mass standards from electrosprays of tetraalkyl ammonium halides, J. Aerosol. Sci., 36, 1224-1237, doi:10.1016/j.jaerosci.2005.02.009, 2005.

Vanhanen, J., Mikkila, J., Lehtipalo, K., Sipila, M., Manninen, H. E., Siivola, E., Petaja, T., and Kulmala, M.: Particle size mag- 
nifier for nano-CN detection, Aerosol. Sci. Tech., 45, 533-542, doi:10.1080/02786826.2010.547889, 2011.

Voisin, D., Smith, J. N., Sakurai, H., McMurry, P. H., and Eisele, F. L.: Thermal desorption chemical ionization mass spectrometer for ultrafine particle chemical composition, Aerosol Sci. Technol., 37, 471-475, 2003.

Wimmer, D., Lehtipalo, K., Franchin, A., Kangasluoma, J., Kreissl, F., Kurten, A., Kupc, A., Metzger, A., Mikkila, J., Petaja, T., Riccobono, F., Vanhanen, J., Kulmala, M., and Curtius, J.: Characterization of diethylene glycol-condensation particle counters for detection of sub-3 nm particles, Nucleation and Atmospheric Aerosols, 1527, 204-207, doi:10.1063/1.4803239, 2013.
Winkler, P. M., Steiner, G., Vrtala, A., Vehkamaki, H., Noppel, M., Lehtinen, K. E. J., Reischl, G. P., Wagner, P. E., and Kulmala, M.: Heterogeneous nucleation experiments bridging the scale from molecular ion clusters to nanoparticles, Science, 319 , 1374-1377, doi:10.1126/science.1149034, 2008.

Zhao, J., Eisele, F. L., Titcombe, M., Kuang, C. G., and McMurry, P. H.: Chemical ionization mass spectrometric measurements of atmospheric neutral clusters using the cluster-CIMS, J. Geophys. Res.-Atmos., 115, D08205, doi:10.1029/2009jd012606, 2010. 